\title{
KOMPETENSI GURU BIOLOGI DALAM MENGEMBANGKAN INSTRUMEN PENILAIAN BERBASIS HIGHER ORDER THINGKING SKILL DI MAN SE KALIMANTAN TENGAH
}

\author{
The Biology Teacher's Competence In Developing Assessment Instrument Based On High Order \\ Thinking Skill At Man In Kalimantan Tengah
}

\author{
Gito Supriadi \\ IAIN Palangka Raya \\ *email: \\ gito.supriadi@iain- \\ palangkaraya.ac.id
}

\begin{abstract}
Abstrak
Tujuan penelitian ini adalah (I) Mendeskripsikan pengetahuan guru Biologi Madrasah Aliyah Negeri tentang instrumen penilaian HOTS. (2) Mengklasifikasikan dimensi berpikir instrument penilaian buatan guru Biologi berdasarkan level kognitif. (3) Mengetahui kompetensi guru Biologi Madrasah Aliyah Negeri dalam mengembangan instrument penilaian HOTS.

Metode yang digunakan dalam penelitian ini menggunakan metode deskriptif dengan pendekatan kuantitatif. Teknik pengumpulan data dengan angket dan dokumentasi. Objek penelitian adalah kompetensi guru biologi dalam mengembangkan instrumen penilaian berbasis Higher Order Thingking Skill (HOTS). Analisis data menggunakan statistik deskriptif dalam bentuk persentase.

Hasil penelitian menunjukkan bahwa : (I) Sebagian besar guru biologi Madrasah Aliyah Negeri di Kalimantan Tengah sudah mengetahui tentang penyusunan instrumen penilaian berbasis HOTS, akan tetapi dalam pelaksanaannya guru masih mengalami kesulitan dalam menyusun soal-soal atau instrumen penilaian yang berbasis HOTS. Hal ini disebabkan guru biologi yang ada di MAN masih banyak yang belum pernah mengikuti pelatihan dalam penyusunan soal-soal yang berbasis HOTS, (2) Klasifikasi instrumen penilaian yang dikembangkan mencakup tingkatan soal $\mathrm{Cl}$ sebesar $22,51 \%$, tingkatan soal $\mathrm{C} 2$ sebesar $19,82 \%$, tingkatan soal C3 sebesar 16,57\%, tingkatan soal C4 sebesar 16,15\%, tingkatan soal C5 sebesar $13,41 \%$ dan tingkatan soal C6 sebesar 11,54\%. (3) Kemampuan guru biologi dalam mengembangkan instrumen penilaian berbasis HOTS dapat dikategorikan kurang baik dengan rata-rata persentase sebesar $41,10 \%$.
\end{abstract}

Kata Kunci:

Kompetensi guru,

Penilaian HOTS

\section{Keywords:}

Teacher's Competence,

HOTS Assessment.

\section{Accepted}

Juli 2021

Published

Agustus 2021

\begin{abstract}
The purpose of this research are : (I) To describe the knowledge of Biology teacher at Madrasah Aliyah Negeri about the HOTS assessment instrument. (2) To classify thinking dimension assessment instrument made by Biology teacher based on cognitive level. (3) To know the Biology teacher's competence at Madrasah Aliyah Negeri in developing HOTS assessment instrument.

This research used descriptive method with quantitative approach. The data collection technique used questionnaire and documentation. The object of this research was Biology teacher's competence in developing assessment instrument based on High Order Thinking Skill (HOTS). The data analysis used descriptive statistic in percentage form.

The result of this research shown that : (I) Mostly the Biology teacher at Madrasah Aliyah Negeri in Kalimantan Tengah already know about the compiling assessment instrument based on HOTS, but in its implementation teacher still difficult compiling the questions or assessment instrument based HOTS. This thing happened because most of biology teacher at MAN not followed training in compiling questions based on HOTS, (2) The classification of assessment instrument that developed $\mathrm{Cl}$ question level in the amount of $22.51 \%, \mathrm{C2}$ question level in the amount of $19.82 \%$, C3 question level in the amount of $16.57 \%$, C4 question level in the amount of $16.15 \%$, C5 question level in the amount of $13.41 \%$ and C6 question level in the amount of $11.54 \%$. (3) The skill of biology teacher in developed assessment instrument based on HOTS can be categorized as not good with the percentage average in the amount of $41.10 \%$.
\end{abstract}




\section{A. Pendahuluan}

Penilaian dalam proses pendidikan merupakan komponen yang tidak dapat dipisahkan dari komponen lainnya khususnya pembelajaran. Penilaian merupakan proses pengumpulan dan pengolahan informasi untuk mengukur pencapaian hasil belajar peserta didik. Penilaian hasil belajar oleh pendidik dilakukan untuk memantau proses, kemajuan belajar, dan perbaikan hasil belajar peserta didik secara berkesinambungan. Penegasan tersebut termaktub dalam Peraturan Pemerintah Nomor 32 Tahun 2013 tentang Perubahan Atas Peraturan Pemerintah Nomor 19 Tahun 2005 tentang Standar Nasional Pendidikan. Dalam Kemendikbud (2018) Penilaian hasil belajar oleh pendidik memiliki peran antara lain untuk membantu peserta didik mengetahui capaian pembelajaran (learning outcomes). Berdasarkan penilaian hasil belajar oleh pendidik, pendidik dan peserta didik dapat memperoleh informasi tentang kelemahan dan kekuatan pembelajaran dan belajar. Dengan mengetahui kelemahan dan kekuatannya, pendidik dan peserta didik memiliki arah yang jelas mengenai apa yang harus diperbaiki dan dapat melakukan refleksi mengenai apa yang dilakukannya dalam pembelajaran dan belajar. Selain itu bagi peserta didik memungkinkan melakukan proses transfer cara belajar tersebut untuk mengatasi kelemahannya (transfer of learning). Sedangkan bagi guru, hasil penilaian hasil belajar oleh pendidik merupakan alat untuk mewujudkan akuntabilitas profesionalnya, dan dapat juga digunakan sebagai dasar dan arah pengembangan pembelajaran remedial atau program pengayaan bagi peserta didik yang membutuhkan, serta memperbaiki rencana pelaksanaan pembelajaran (RPP) dan proses pembelajaran pada pertemuan berikutnya.

Pelaksanaan penilaian hasil belajar oleh pendidik merupakan wujud pelaksanaan tugas profesional pendidik sebagaimana tertuang dalam Undang-Undang Nomor I4 tahun 2005 tentang Guru dan Dosen. Penilaian hasil belajar oleh pendidik tidak terlepas dari proses pembelajaran. Oleh karena itu, penilaian hasil belajar oleh pendidik merupakan salah satu kompetensi yang harus dimiliki oleh guru pada aspek pedagogik. Mardapi (2017) menegaskan kualitas pembelajaran ini dapat dilihat dari hasil penilaiannya. Penilaian yang baik akan mendorong pendidik untuk menentukan strategi mengajar yang baik dan memotivasi peserta didik untuk belajar yang lebih baik. Oleh karena itu upaya peningkatan kualitas pendidikan diperlukan perbaikan sistem penilaian.

Penilaian merupakan kegiatan sangat penting dalam pembelajaran dan dapat memberikan umpan balik yang konstruktif bagi guru maupun peserta didik termasuk salah satunya adalah mata pelajaran Biologi di Madrasah Aliyah. Salah satu kompetensi inti yang harus dicapai oleh peserta didik dalam mata pelajaran Biologi di SMA/MA adalah mengolah, menalar, dan menyaji dalam ranah konkret dan ranah abstrak terkait dengan pengembangan dari yang dipelajarinya di sekolah secara mandiri, dan mampu menggunakan metoda sesuai kaidah keilmuan. Guna mencapai kompetensi inti tersebut salah usaha yang dilakukan guru adalah membuat instrument penilaian yang dapat melatih peserta didik untuk memiliki keterampilan berpikir tingkat tinggi.

Penilaian hasil belajar diharapkan dapat membantu peserta didik untuk meningkatkan kemampuan berpikir tingkat tinggi (Higher Order Thinking Skills/HOTS), karena berpikir tingkat tinggi dapat mendorong peserta didik untuk berpikir secara luas dan mendalam tentang materi pelajaran. Helmawati (2019), Higher order thinking skills (HOTS) atau keterampilan berpikir tingkat tinggi merupakan bagian dari taksonomi Bloom hasil revisi oleh Anderson dan Krartwohl (200I) yang terdiri dari Menganalisis (C4), Mengevaluasi (C5), dan Mengkreasi (C6). Guru harus memiliki pengetahuan dan keahlian untuk menunjang pekerjaannya, sehingga dapat mengembangkan keterampilan berpikir tingkat tinggi peserta didik.

Dikdasmen (2017) Penilaian pembelajaran berbasis keterampilan berpikir tingkat tinggi atau berpikir kritis direkomendasikan untuk diselenggarakan dalam proses pendidikan yang bermutu. Implementasi pembelajaran dan penilaian berbasis Higher Order Thingking Skill (HOTS) diharapkan mampu meningkatkan mutu dan kompetensi lulusan dalam rangka menghadapi era persaingan bebas pada rovolusi industry 4.0. 
Penelitian serupa telah dilakukan oleh Edi Istiyono, Djemari Mardapi, dan Suparno (2014) dengan judul Pengembangan Tes Kemampuan Berpikir Tingkat Tinggi Fisika (PsysHOTS) Peserta Didik SMA, dengan kesimpulan bahwa Instrument PhysTHOTS dikembangkan dalam bentuk pilihan ganda beralasan pada kemampuan menganalisis, mengevaluasi, dan menciptakan untuk materi fisika gerak, gaya, usaha dan energi, serta momentum dan implus yang terdiri atas perangkat tes $A$ dan perangkat tes $B$ yang masing-masing terdapat 26 item dengan 8 anchor item. (2) Instrumen PhysTHOTS telah memenuhi validitas isi dengan expert judgment dan telah mendapatkan bukti empiris validitas konstruk fit pada Partial Credit Model (PCM) berdasarkan data politomus empat kategori. Seluruh item pada PhysTHOTS dalam kriteria baik karena tingkat kesulitannya berada pada rentang antara $-2,00$ sampai dengan 2,00. Penelitian Endah Putri Novi Arti (20I5), hasil penelitian diketahui bahwa kemampuan guru Biologi dalam membuat soal
HOT berdasarkan taksonomi Bloom di SMA Negeri I Wonosari Klaten sangat kurang baik (2I,2\%) yaitu soal C4 (I5,2\%), C5 (3,0\%), C6 $(3,0 \%)$ dan soal LOT sangat baik $(78,8 \%)$ yaitu soal CI (3I,I\%), C2 (29,8\%), C3 (17,9\%).

\section{B. Metode Penelitian}

Metode yang digunakan dalam penelitian ini adalah dengan pendekatan kuantitatif, dengan analisis deskriptif. Populasi penelitian adalah guru biologi di Madrasah Aliyah Negeri (MAN) se Kalimatan Tengah. Sampel penelitian dengan teknik sampel jenuh (Sugiyono, 20I3), sehingga semua guru biologi yang ada di MAN dijadikan sampel dengan jumlah 25 orang.

Teknik analisis data yang dilakukan adalah membuat klasifikasi bentuk instrumen penilaian yang dikembangkan oleh guru biologi ditinjau dari ranah kognitif, yang selanjutnya menghitung persentase jumlah soal yang dikembangkan, dengan kriteria sebagai berikut:

Tabel I

Kriteria Kompetensi Guru dalam Mengembangkan Instrumen

Penilaian Berbasis HOTS

\begin{tabular}{|c|c|}
\hline Kriteria & Persen \\
\hline Sangat Baik & $76-100$ \\
\hline Baik & $5 I-75$ \\
\hline Cukup Baik & $26-50$ \\
\hline Kurang Baik & $0-25$ \\
\hline
\end{tabular}

\section{Hasil Penelitian dan Pembahasan}

\section{Pengetahuan Guru Biologi Madrasah Aliyah Negeri terhadap instrumen penilaian HOTS}

Guna memperoleh data terkait dengan pengetahuan guru tentang instrumen penilaian berbasis High Order Thinking Skill (HOTS), digunakan teknik wawancara terstruktur dan angket. Pengetahuan guru yang dimaksud adalah wawasan dan pengalaman yang diperoleh guru terkait dengan penyusunan instrumen penilaian berbasis HOTS.
Pengetahuan guru dalam Menyusun instrumen penilaian berbasis HOTS dirasa penting sebagai sarana untuk menumbuhkan kemampuan berpikir kritis dan logis dari siswa. Peningkatan kompetensi guru dalam menulis soal HOTS yang masih belum terbiasa membutuhkan dorongan dan motivasi dari lembaga yang menaunginya, salah satunya adalah Madrasah Aliyah melalui Kementerian Agama.

Berdasarkan data yang diperoleh bahwa dari 25 orang guru biologi hanya 9 orang yang pernah 
mengikuti pelatihan dan 16 orang tidak pernah megikuti pelatihan penulisan soal bebasis HOTS. hal ini tentunya harus menjadi perhatian khusus terutama oleh pihak kementerian agama agar memberikan pelatihan khusus bagi guru-guru di madrasah untuk dilatih Menyusun soal atau instrumen penilaian berbasis HOTS.

Soal HOTS adalah soal yang dapat merangsang siswa untuk menjawab pertanyaan yang mengukur kompetensi siswa dengan tepat sesuai indikator. Soal HOTS bukan hanya mengingatkan ataupun menghitung, tetapi juga soal yang dapat mengembangkan kreativitas dan keterampilan berpikir kritis siswa.

Guru Biologi Madrasah Aliyah Negeri (MAN) di Kalimantan Tengah 100\% telah mengetahui tentang penyusunan soal berbasis High Order Thinking Skill (HOTS). Terkait dengan kegiatan mengikuti pelatihan penyusunan soal berbasis HOTS terdapat 9 orang guru atau $16 \%$ yang menyatakan pernah mengikuti pelatihan dan sebanyak 16 orang atau $64 \%$ tidak pernah mengikuti pelatihan penyusunan soal berbasis HOTS. Sedangkan guru yang menyatakan kesulitan dalam penyusunan soal berbasis HOTS sebanyak 16 orang dan yang menyatakan tidak kesulitan dalam Menyusun soal HOTS sebanyak 9 orang. Berdasarkan data tersebut dapat dikatakan bahwa sebagian besar guru biologi Madrasah Aliyah Negeri di Kalimantan Tengah sudah mengetahui tentang penyusunan instrumen penilaian berbasis HOTS, akan tetapi dalam pelaksanaannya sebagian besar guru masih mengalami kesulitan dalam menyusun soal-soal atau instrumen penilaian yang berbasis HOTS. Hal ini disebabkan guru biologi yang ada di MAN masih banyak yang belum pernah mengikuti pelatihan dalam penyusunan soal-soal yang berbasis HOTS.

Berdasarkan data di atas. tentunya harus menjadi perhatian khusus terutama oleh pihak kementerian agama agar memberikan pelatihan khusus bagi guru-guru di madrasah untuk dilatih Menyusun soal atau instrumen penilaian berbasis HOTS.

2. Klasifikasi Instrumen Penilaian Buatan Guru Biologi Ditinjau dari Level Kognitif

Berdasarkan

dari

keseluruhan klasifikasi instrumen yang dikembangkan oleh guru biologi MAN se Kalimantan Tengah, maka secara umum dapat diperoleh gambaran bahwa klasifikasi instrumen yang dikembangkan mencakup tingkatan soal $\mathrm{Cl}$ sebesar $22,51 \%$, tingkatan soal C2 sebesar 19,82\%, tingkatan soal C3 sebesar $16,57 \%$, tingkatan soal C4 sebesar $16,15 \%$, tingkatan soal C5 sebesar $13,41 \%$ dan tingkatan soal C6 sebesar $11,54 \%$.

Gambaran klasifikasi instrumen penilaian yang dikembangkan guru biologi di MAN dapat dilihat pada diagram berikut: 


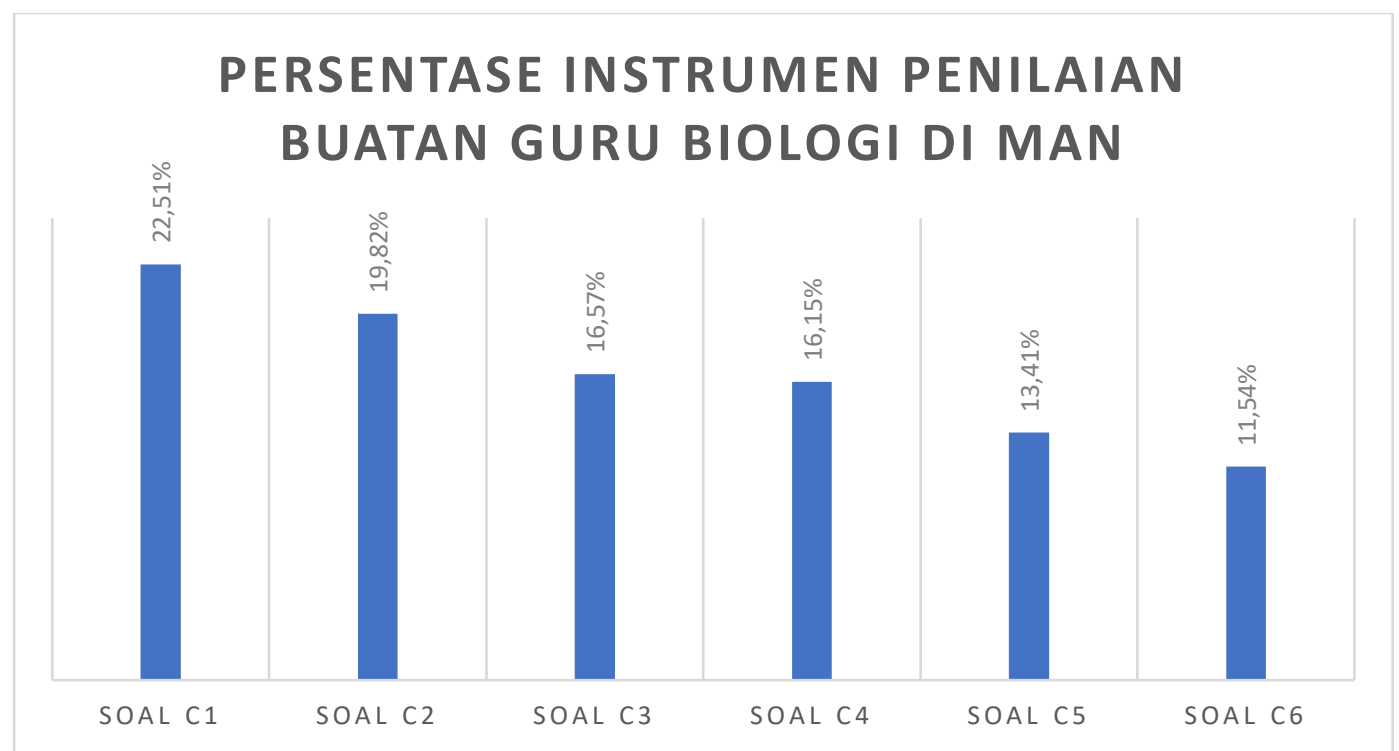

Gambar I Diagram Klasifikasi Instrumen Penilaian yang dikembangkan guru Biologi di MAN se Kalimantan Tengah Berdasarkan Level Kognitif

Dari keenam tingkatan tersebut dibagi menjadi 2 (dua) level yaitu level LOTS yaitu terdiri dari $\mathrm{Cl}, \mathrm{C} 2$, dan $\mathrm{C} 3$ sebesar $58,90 \%$ dan level HOTS terdiri dari C4, C5, dan C6 sebesar $41,10 \%$. Berdasarkan klasifikasi tersebut dapat dikategorikan bahwa klasifikasi pengembangan instrumen yang dibuat guru biologi masih didominasi soal yang LOTS dengan kategori baik dan sedangkan pengembangan instrumen penilaian level HOTS lebih kecil persesntasenya yaitu $4 \mathrm{I}, 10 \%$ dengan kategori cukup baik.

Klasifikasi

instrumen penilaian level LOTS dan HOTS dapat dilihat pada diagram berikut:

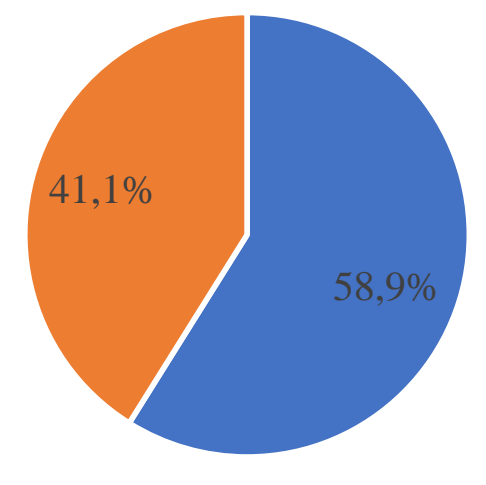

- Soal LOTS - Soal HOTS

Gambar 2 Diagram Klasifikasi Instrumen Penilaian yang dikembangkan guru Biologi di MAN se Kalimantan Tengah Berdasarkan Level LOTS dan HOTS

\section{Kompetensi Guru Biologi} Madrasah Aliyah Negeri dalam
Mengembangkan Instrumen Penilaian Berbasis HOTS 
Kompetensi guru biologi Madrasah Aliyah Negeri di Kalimantan Tengah dalam membuat soal HOT dikategrikan cukup baik $(41,10 \%)$ dan LOT dikategorikan baik (58,90\%). Kemampuan guru biologi Madrasah Aliyah Negeri di Kalimantan Tengah dalam membuat soal HOT tingkatn kognitif C4 $(16,15 \%)$ merupakan persentase tertinggi tingkatan soal HOT dibanding dengan persentase tingkatan kognitif soal HOT lainnya yaitu tingkatan C5 (13,4l\% dan C6 (I I,54\%). Hal ini dikarenakan membuat soal C4 lebih mudah dibandingkan dengan soal $\mathrm{C} 5$ dan C6. Sedangkan kemampuan guru biologi Madrasah Aliyah Negeri di Kalimantan Tengah dalam membuat soal LOT pada tingkatan $\mathrm{Cl}$ $(22,51 \%)$ juga merupakan persentase tertinggi tingkatan kogtitif soal LOT dibanding dengan tingkatan kognitif soal LOT lainnya yaitu tingkatan kognitif C2 $(19,82 \%$, dan tingkatan kognitif C3 (16,57\%), karena soal $\mathrm{Cl}$ lebih mudah dibuat guru dan lebih mudah dikerjakan peserta didik, namun dalam hal tersebut akan menyebabkan kemampuan peserta didik cenderung hanya menghafal materi untuk mendapatkan nilai baik, serta rasa ingin tahu peserta didik berkurang sehingga kemampuan peserta didik untuk membuat hal baru akan menjadi rendah.

Dengan

demikian menunjukkan bahwa kompetensi guru biologi dalam mengembangkan instrumen penilaian berbasis HOTS dapat dikategorikan cukup baik dengan rata-rata persentase sebesar $41,1 \%$.

Menurut Abdul Majid dan Aep S. Firdaus (2014) terdapat 5 (lima) indikator kompetensi penilaian dan evaluasi yang dijadikan ukuran dalam penilaian kinerja guru, yaitu:

I) Guru mampu menyusun alat penilaian yang sesuai dengan tujuan pembelajaran untuk mencapai kompetensi tertentu seperti yang tertulis dalam RPP;

2) Guru mampu melakukan penilaian dengan berbagai tehnik dan jenis penilaian, selain penilaian formal yang dilaksanakan sekolah, dan mengumumkan hasil serta implikasinya kepada peserta didik, tentang pemahaman terhadap materi pembelajaran yang telah dan akan dipelajari;

3) Guru harus mampu menganalisis hasil penilaian untuk mengidentifikasi topic kompetensi dasar yang sulit sehingga diketahui kekuatan dan kelemahan masing-masing peserta didik untuk keperluan remedial dan pengayaan;

4) Guru mampu memanfaatkan masukan dari peserta didik dan merefleksikannya untuk meningkatkan pembelajaran selanjutnya, dan dapat membuktikannya melalui catatan, jurnal pembelajaran, rancangan pembelajaran, materi tambahan, dan sebagainya;

\section{Simpulan}

I. Sebagian besar guru biologi Madrasah Aliyah Negeri di Kalimantan Tengah sudah mengetahui tentang penyusunan instrumen penilaian berbasis HOTS, akan tetapi dalam pelaksanaannya guru masih mengalami kesulitan dalam menyusun soal-soal atau instrumen penilaian yang berbasis HOTS. Hal ini disebabkan guru biologi yang ada di MAN masih banyak yang belum pernah mengikuti pelatihan dalam 
penyusunan soal-soal yang berbasis HOTS.

2. Klasifikasi instrumen penilaian yang dikembangkan mencakup tingkatan soal $\mathrm{Cl}$ sebesar $22,5 \mathrm{I} \%$, tingkatan soal C2 sebesar $19,82 \%$, tingkatan soal C3 sebesar 16,57\%, tingkatan soal C4 sebesar 16,15\%, tingkatan soal C5 sebesar $13,41 \%$ dan tingkatan soal C6 sebesar II,54\%.

3. Kemampuan guru biologi dalam mengembangkan instrumen penilaian berbasis HOTS dapat dikategorikan cukup baik dengan rata-rata persentase sebesar $41,10 \%$.

\section{DAFTAR PUSTAKA}

Abdul Majid dan Aep S. Firdaus, 2014, Penilaian Autentik Proses dan Hasil Belajar, Bandung: Interes Media.

Direktorat Jenderal Guru dan Tenaga Kependidikan Kementerian Pendidikan dan Kebudayaan, 2018, Buku Penilaian Berorientasi Higher Order Thingking Skills Program Peningkatan Kompetensi Pembelajaran Berbasis Zonasi.

Direktorat Jenderal Pendidikan Dasar dan Menengah, 2017, Panduan Penilaian oleh Pendidik dan Satuan Pendidikan Sekolah menengah Atas, Jakarta.

Djemari Mardapi, 2017, Pengukuran, Penilaian dan Evaluasi Pendidikan, Yogyakarta: Parama Publishing.

Edi Istiyono, Djemari Mardapi, Suparno, 2014. Pengembangan Tes Kemampuan Berpikir Tingkat Tinggi Fisika (PhysTHOTS) Peserta Didik SMA, Jurnal Penelitian dan Evaluasi Pendidikan, Tahun 18, Nomor I, 2014.

Endah Putri Novi Arti. 2015. Kemampuan Guru Mata Pelajaran Biologi dalam Pembuatan Soal Higher Order Thingking Skill, di SMA Negeri I Wonosari Klaten,

Helmawati, 2019, Pembelajaran dan Penilaian Berbasis HOTS, Bandung: Remajarosdakarya.

Peraturan Pemerintah Nomor 19 Tahun 2005 Tentang Standat Nasional Pendidikan.

Sugiyono, 2013, Statistik Untuk Penelitian, Bandung: Alfabeta.

Undang Nomor 14 tahun 2005 tentang Guru dan Dosen 